\title{
Detection of persistent ductus in hypoplastic left heart syndrome by contrast echocardiography
}

\author{
CARLOS MORTERA, GREGORIO LEON \\ From Servicio de Cardiologia, Centro Médico Nacional Valdecilla, Santander, Spain
}

SUMMARY A patient with hypoplastic left heart syndrome was studied using contrast echocardiography after peripheral venous injection of dextrose. The combination of the parasternal and suprasternal approach allowed for identification of the right ventricular cavity, excluded the presence of right-to-left intracardiac shunts, and established normal ventriculoarterial connections.

From the abdominal approach, the abdominal aorta was identified as an echo-free space corresponding to this structure in position, which became opacified after peripheral injection of dextrose into the left-hand vein.

In view of the suprasternal and parasternal findings opacification of the abdominal aorta could only have occurred in the presence of a pulmonary artery to descending aorta shunt through a persistent ductus arteriosus.

Echocardiography is a reliable method for establishing the diagnosis of the hypoplastic left heart syndrome, and has the advantage of avoiding cardiac catheterisation in sick newborn babies. ${ }^{12}$

The echocardiographic detection of a big right ventricular cavity in the presence of a small left ventricular cavity and aortic root, together with the hypoplastic or absent mitral valve, has been taken as diagnostic of the syndrome. ${ }^{345}$

Peripheral venous injection of dextrose as an ultrasonic indicator has been used in the echocardiographic detection of right-to-left shunts, ${ }^{6}$ and as a complementary method in the echocardiographic assessment of ventriculoarterial connections. ${ }^{\text {? }}$

The purpose of this paper is to present the characteristic filling patterns obtained from the parasternal, suprasternal, and abdominal approaches in this condition using peripheral venous injections of 5 per cent dextrose as ultrasonic indicator.

\section{Case report}

A 24-hour-old baby who had been born at term and weighed $2850 \mathrm{~g}$ was admitted to hospital in severe heart failure. On clinical examination there was dyspnoea, tachypnoea, and subcostal recession. The infant was pale with minimal central cyanosis. The peripheral pulses were slight but palpable, and the blood pressure in the four limbs was $40 \mathrm{mmHg}$ by the flush method. There was right ventricular hypertrophy clinically, and on auscultation the first heart sound was loud, and the second heart sound was also loud and single. A pansystolic murmur grade $3 / 6$ was heard at the left sternal edge, and a third heart sound was present at the apex. The liver was $4 \mathrm{~cm}$ below the costal margin. The electrocardiogram showed sinus rhythm with a heart rate of 150 per minute, and right atrial and right ventricular enlargement. The frontal axis was $+130^{\circ} . X$-ray film of the chest showed cardiomegaly with a cardiothoracic ratio of 65 per cent, plethoric lung fields, and a narrow pedicle.

Echocardiography from the parasternal views showed a large right ventricular cavity $(14.7 \mathrm{~mm})$, a small left ventricular cavity $14 \mathrm{~mm}$, and a small aortic root, $5 \cdot 2 \mathrm{~mm}$. The left atrium was enlarged $12 \mathrm{~mm}$, and the pulmonary artery was also enlarged at $11.5 \mathrm{~mm}$ diameter. The four valves of the heart were visualised in the standard way. ${ }^{8}$ The mitral valve was very small, though two leaflets could be seen. The aortic valve was visualised as a collection of thick echoes within the aortic root. The pulmonary valve was large and showed several of the features indicative of pulmonary hypertension. ${ }^{9}$ The tricuspid valve was normal.

An intravenous cannula was fixed into a vein on 
the back of the baby's left hand, and peripheral injections of 5 per cent dextrose were made. From the parasternal view, after the injection, the right ventricle was completely opacified defining the interventricular septal wall, and the left ventricle remained free of contrast (Fig. 1B).

Slight angulation towards the aortic root and left atrium allowed the small aortic valve and big pulmonary artery to be visualised. Contrast injection opacified only the anterior great artery.
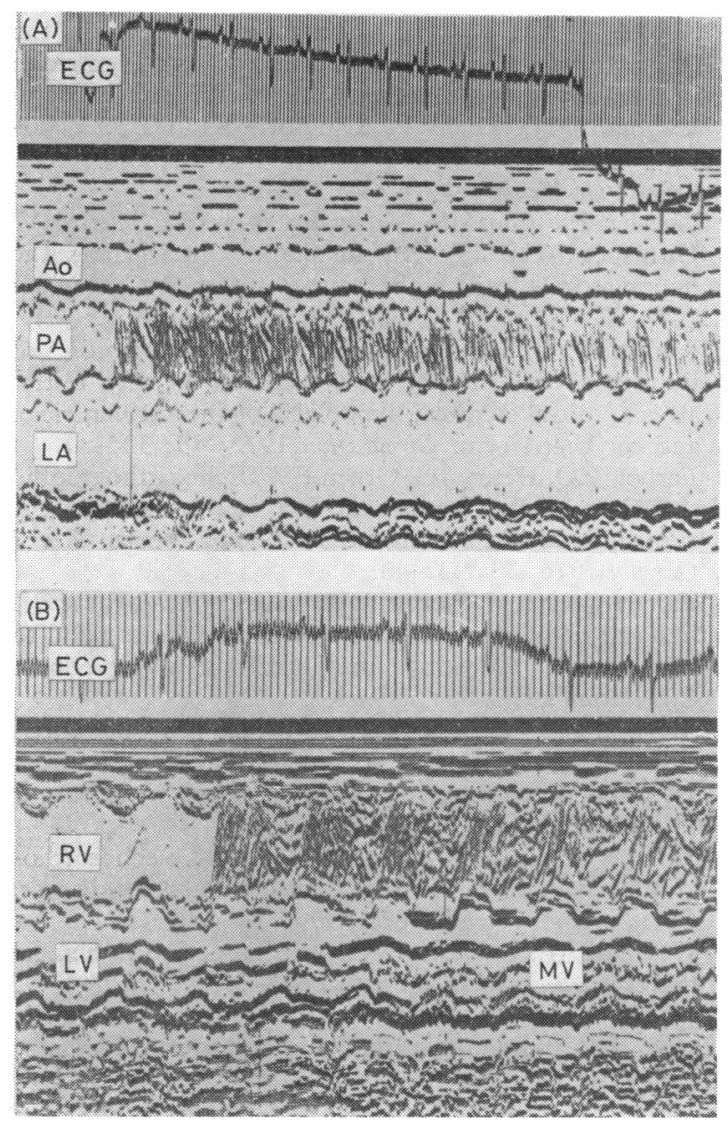

Fig. 1 (A) Echocardiogram obtained from the suprasternal view. The aorta $(A o)$, the pulmonary artery $(P A)$, and the left atrium ( $L A)$ are seen in the same echocardiographic plane. After peripheral venous injection of contrast, only the PA is opacified, suggesting that the ventriculoarterial connections are normal, with no evidence of a right-to-left intracardiac shunt.

(B) This echocardiogram has been recorded from the parasternal approach. The right ventricle $(R V)$ and the left ventricle $(L V)$ are seen in the same cut. After injection of 5 per cent dextrose into the baby's hand only the $R V$ is opacified. No right-to-left shunt is detected. The mitral valve (MV) is visualised as a hypoplastic valvular structure.
The transducer was then placed in the suprasternal notch and the aortic arch, pulmonary artery, and left atrium were located. ${ }^{10}$ The aortic arch was smaller than the pulmonary artery, $2.5 \mathrm{~mm}$ diameter as against $10 \mathrm{~mm}$ diameter. After peripheral venous injection only the pulmonary artery was opacified.

The combination of these two approaches excluded a right-to-left intracardiac shunt, and established a normal ventriculoarterial connection. ${ }^{?}$

The transducer was then placed in the abdomen to localise the abdominal aorta, and after peripheral venous injection, a small posterior echo-free space was opacified (Fig. 2). There was cyclical opacification after contrast injection, the contrast being more intense in systole than in diastole. The injection was repeated three times, with identical results, and the structure was therefore taken to represent the abdominal aorta filling through a persistent ductus arteriosus from the pulmonary artery, which in turn received its contrast directly from the heart. From previous experience with the technique the cyclical opacification eliminated the possibility that this was the inferior vena cava or other great vein. ${ }^{11}$

Unfortunately, 20 hours after the investigation the baby died before cardiac catheterisation was done.

At necropsy the right atrium was large with an intact atrial septum. It connected with a dilated right ventricle through a normal tricuspid valve and from this ventricle a big pulmonary artery arose. There was a persistent ductus arteriosus

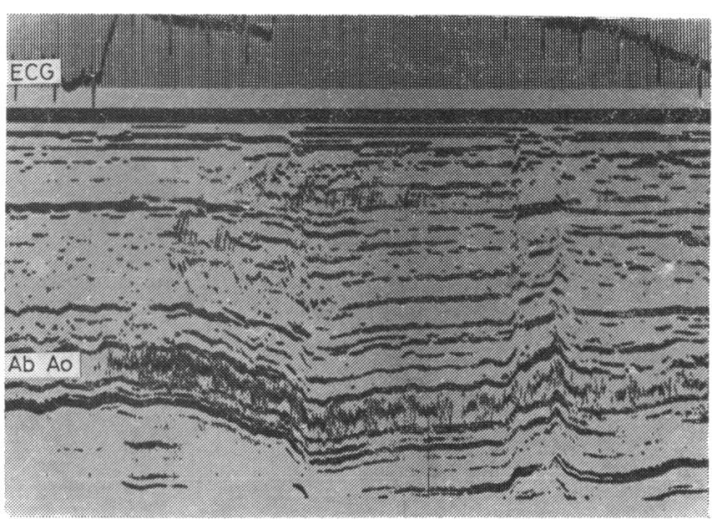

Fig. 2 Echocardiogram performed from the baby's abdomen; linear echoes are visualised. After peripheral left-hand injection, opacification of the abdominal aorta ( $A b \mathrm{Ao}$ ) occurs. Intense systolic opacification is followed by slight diastolic attenuation. In the absence of an intracardiac right-to-left shunt, this filling pattern represents a pulmonary artery-descending aorta shunt in the presence of a persistent ductus arteriosus. 
with a diameter of $3 \mathrm{~mm}$. The left atrium was normal, and received all four pulmonary veins. The mitral valve was hypoplastic and had two welldefined anterior and posterior leaflets, with two small papillary muscles. The left ventricle was hypoplastic (diameter $16 \mathrm{~mm}$ ) with thick walls and pronounced endocardial fibroelastosis, and gave rise to a bicuspid hypoplastic aortic valve and a small ascending aorta with a diameter of $6 \mathrm{~mm}$. The coronary arteries were normal though the aortic arch was small, $3.5 \mathrm{~mm}$. There was evidence of heart failure.

\section{Discussion}

Echocardiography is a reliable method of defining intracardiac anatomy. In sick neonates with hypoplastic left heart syndrome, echocardiography can give a definitive diagnosis without recourse to cardiac catheterisation. ${ }^{12}$

However, when only one atrioventricular valve is visualised echocardiographically, it is often difficult to differentiate the hypoplastic left heart syndrome from other conditions with one functional atrioventricular valve. On occasions the interventricular septum can only be reliably identified using contrast studies. Therefore, in these children there are three reasons for using contrast echocardiography before catheterisation is done: firstly, to define the limits of cardiac cavities, which may be obscure; secondly, to detect right-to-left intracardiac shunts; and thirdly, to establish ventriculoarterial connections. ${ }^{7}$ In this case the views from the parasternal approach showed a big right ventricle and a small left ventricle. Contrast echocardiography delineated the right ventricular walls and showed absence of right-to-left shunts at intracardiac level (Fig. 1B). The suprasternal approach showed the opacification of the pulmonary artery only, from which we deduced that ventriculoarterial connections were normal (Fig. 1A).

When the transducer was placed on the abdomen several linear echoes were seen but there was not enough definition to identify the abdominal aorta with certainty. However, after peripheral venous injections into the left hand, contrast echoes filled the space between the two linear echoes (Fig. 2).

This pattern of filling, shown by peripheral injections of dextrose, and using the parasternal and the suprasternal transducer positions, indicated that the contrast injected into the left hand could only reach the abdominal aorta through a right-toleft shunt via a persistent ductus arteriosus.

The use of different transducer positions together with peripheral contrast echocardiography can increase diagnostic accuracy in complex cardiac anomalies; in the absence of intracardiac right-toleft shunts the opacification of the abdominal aorta demonstrates the presence of a persistent ductus arteriosus with reverse ductal shunting.

\section{References}

${ }^{1}$ Meyer RA, Kaplan S. Echocardiography in the diagnosis of hypoplasia of the left or right ventricles in the neonate. Circulation 1972; 46: 55-64.

${ }^{2}$ Godman MJ, Tham P, Langford Kidd BS. Echocardiography in the evaluation of cyanotic newborn infant. Br Heart F 1974; 36: 154-66.

${ }^{3}$ Chesler E, Joffe HS, Vecht R, Beck W, Schrire V. Ultrasound cardiography in single ventricle and the hypoplastic left and right heart syndromes. Circulation 1970; 42: 123-9.

${ }^{4}$ Lundström N-R. Ultrasound cardiographic studies of the mitral valve region in young infants with mitral atresia, mitral stenosis, hypoplasia of the left ventricle, and cor triatriatum. Circulation 1972; 45: 324-34.

${ }^{5}$ Farooki ZQ, Henry JC, Green EW. Echocardiographic spectrum of the hypoplastic left heart syndrome. A clinicopathologic correlation in 19 new borns. Am f Cardiol 1976; 38: 337-43.

${ }^{6}$ Valdés-Cruz LM, Pieroni DR, Roland JA, Vaghese BJ. Echocardiographic detection of intercardiac right to left shunts following peripheral vein injections. Circulation 1976; 55: 558-62.

${ }^{7}$ Mortera C, Hunter S, Tynan M. Diagnosis of ventriculoarterial discordance (transposition of the great arteries) by contrast echocardiography. Br Heart $\mathcal{f}$ 1977; 39: 844-46.

${ }^{8}$ Solinger R, Elbl F, Minhas K. Deductive echocardiographic analysis in infants with congenital heart disease. Circulation 1974; 50: 1072-96.

${ }^{9}$ Weyman AE. Pulmonary valve echo motion in clinical practice. $A m$ f Med 1977; 62: 843-55.

${ }^{10} \mathrm{Goldberg}$ BB. Ultrasonic measurement of the aortic arch, right pulmonary artery and left atrium. Radiology $1971 ; 101$ : 383-90.

${ }^{11}$ Mortera C, Hunter S, Tynan M. Contrast echocardiography and the suprasternal approach in infants and children. Eur f Cardiol 1979; 9: 437-54.

Requests for reprints to Dr Carlos Mortera, Servicio Cardiologia, Centro Medico Nacional Valdecilla, Santander, Spain. 